\title{
Influence of Migration and Plugging of Nanoparticles on Coal Permeability in Coal Reservoirs
}

\author{
Xiaopeng Zhai $\mathbb{D}^{1},{ }^{1}$ Weihong Chen ${ }^{\mathbb{D}},{ }^{1}$ Yun Xu, ${ }^{2}$ Yishan Lou ${ }^{\mathbb{D}},{ }^{1}$ Shuhong Xu, ${ }^{2}$ \\ Lihui Zheng $\mathbb{B}^{1,3}$ Zhiyang Guo $\mathbb{D}^{1},{ }^{1}$ Yuanchang Chen $\mathbb{D}^{\mathrm{D}},{ }^{4}$ Hongyong Hao, ${ }^{5}$ \\ and Jianfang Jiang $\mathbb{D}^{3}$ \\ ${ }^{1}$ Lost Circulation Prevention and Control Laboratory, National Engineering Laboratory for Oil and Gas Drilling Technology, \\ Yangtze University, Wuhan, Hubei 430100, China \\ ${ }^{2}$ Research Institute of Petroleum Exploration \& Development, PetroChina, Beijing 100083, China \\ ${ }^{3}$ College of Petroleum Engineering, China University of Petroleum (Beijing), Beijing 102249, China \\ ${ }^{4}$ Structural Dynamics and Acoustic Systems Laboratory, University of Massachusetts Lowell, Lowell, Massachusetts 01854, USA \\ ${ }^{5}$ Research Institute of Experiment and Detection, Xinjiang Oilfield Company, PetroChina, Karamay, Xinjiang 834000, China
}

Correspondence should be addressed to Lihui Zheng; 782617871@qq.com

Received 4 September 2020; Revised 2 October 2020; Accepted 4 August 2021; Published 23 August 2021

Academic Editor: Nicolò Colombani

Copyright ( 2021 Xiaopeng Zhai et al. This is an open access article distributed under the Creative Commons Attribution License, which permits unrestricted use, distribution, and reproduction in any medium, provided the original work is properly cited.

\begin{abstract}
The plugging of nanopores in low-permeability coal reservoirs is an important factor that affects productivity reduction. However, the mechanism of plugging of the nanopores in coal reservoirs remains unclear. In this study, the coal samples from the Anze coalbed methane block of the North China Oilfield are used as the research object. Experiments are conducted on the mechanism of nanopore plugging by the variation of nanopore permeability based on the pressure oscillation method and the nanopore (scanning electron microscope) method. The research shows that the foreign working fluid invades a coal sample; the sample changes from being hydrophobic to being water absorbent within a certain period. The instability caused by the expansion of coal clay mineral particles promotes the dispersion and shedding of particles, and the migration of particles is accelerated under the shear stress of the working fluid. In addition, the viscosity and pressure difference of the working fluid are important factors that affect particle plugging. The viscosity of the fluid increased by two times, and permeability decreased by 1.21 times. As the pressure difference increases by two times, permeability can be reduced by up to two orders of magnitude. The findings of this study can help for better understanding of the mechanism of plugging of the nanopores in coal reservoirs and the reasons of production reduction in low-permeability coal reservoirs. Such findings provide theoretical support for the selection of the working fluid, and reasonable production pressure difference can effectively reduce the damage on coal permeability in a low-permeability coal reservoir.
\end{abstract}

\section{Introduction}

Most of the coalbed methane resources in China have low porosity and low permeability. Improving the permeability of low-permeability coal seams to improve the economic benefits of coalbed methane mining has elicited increasing attention from industry researchers $[1,2]$. The pore size of coal reservoirs is usually at the nanoscale, leading to the diversity of coalbed methane occurrence states [3-5]. This occurrence state's diversity leads to complex reservoir devel- opment, large differences in the production capacity of wells, and low single-well production $[6,7]$. Therefore, research on the pore structure of coalbed methane reservoirs has had considerable attention by academic and industrial researchers.

Studies on the pore structure of coalbed reservoirs have focused on the analysis of microstructure characteristics, establishment of pore quantitative evaluation methods, and determination of the water absorption and production mechanisms of coalbed methane; these studies provide a 
theoretical foundation for research on the permeability damage of coal seams with nanopores [8-13]. Their results showed that coal pores are mostly nanoscale pores and vulnerable to reservoir damage caused by external fluid pollution $[14,15]$.

However, most recent studies have focused on the influence of different factors on coal reservoir permeability from a macroperspective, with little consideration given to the study of microstructure coal seam permeability [16-20]. Macroscopic research has shown that the permeability damage of coalbed methane originates from two main aspects. The first reason is the damage caused by clay expansion and water lock resulting from the invasion of the working fluid into the reservoir and the damage caused by fluid incompatibility. Mitra et al. [21] conducted a linear expansion rate experiment on soaked coal samples and found that the drilling fluid invasion into the coal rock results in coal rock expansion, which reduces the permeability of the coal and damages the coal rock reservoir. Yang et al. [22] believed that if clear water is incompatible with the reservoir fluid, then a chemical reaction might occur, and insoluble inorganic scales (e.g., calcium, magnesium, barium, and iron salts) could form and accumulate in the pore fracture of the coal rock, resulting in decreased coal rock permeability and reservoir damage. Liu et al. [23] reported that the damage on a coal reservoir depends on the mineral composition, pressure, injection velocity, injection fluid composition, $\mathrm{pH}$ value, and other variables of the reservoir; meanwhile, pressure difference, water sensitivity damage, and drilling fluid compatibility are the main factors of reservoir damage during coalbed methane drilling.

The second reason is the stress sensitivity damage to coal reservoirs. Li et al. [24] reported that the coal core has strong stress sensitivity; as the pollution pressure increases, the coal core's permeability recovery value decreases sharply. The initial stress sensitivity coefficient of the artificial fracture coal sample tested by Karacan et al. [25] was 0.73 , but the value became 0.79 after drilling fluid treatment. This result indicates that the drilling fluid filtrate's invasion during the drilling process strengthened the stress sensitivity of the reservoir. According to Yue et al. [15], the main factors of coal reservoir damage are a solid phase in the drilling fluid, water sensitivity, pressure sensitivity, and polymer plugging. The coal core has low porosity and permeability and high clay mineral content and is easy to be damaged by solid and liquid phase pollution during drilling. Therefore, the research on coal permeability damage should focus on the factors of fluid and pressure difference.

The macroscopic permeability damage of coalbed methane reservoirs directly reflects the influence of various factors on coal permeability, thus providing theoretical support for selecting the coalbed reservoir protection drilling fluid [15, 26-28]. Coal drilling fluids, such as clear water, salt water system, foam system, cashmere bag system, and polymer system, are formed in different coal seams. This formation, to some extent, reduces the damage to the coal reservoir and improves permeability. However, a rapid decrease in coal reservoir permeability still occurs because most coal reservoirs have ultralow permeability, and the coal matrix permeability is generally less than 2-10 millidarcys [23, 29-32]. No research has been conducted on the permeability damage mechanism of this type of microporous coal reservoir. However, a few studies have examined the nanoscale pore permeability's characterization and the factors that affect permeability damage.

The pore structure of nanoscale coal reservoirs is complex, and the pore diameter is small; hence, working and characterizing permeability is difficult [33]. In a nanoscale coal reservoir, the flow of fluid through the rock is too small, and the amount of time required to establish the steady-state flow is too large; in addition, the measurement results are inaccurate, the permeability of the sample cannot be measured sometimes, and the conventional Darcy's law permeability test is challenging to apply to this type of reservoir structure [34]. The calculation method's accuracy is also difficult to guarantee because of the uncertain boundary conditions during the calculation of core permeability in pressure drop measurement. The NMR test's permeability is affected by the signal-to-noise ratio, and errors occur [35-39]. Nanopore permeability reduction is a complex process, and no accurate and effective measurement method is available [40, 41]. Evidently, the research on the factors that influence nanopore permeability progresses gradually.

In summary, as a typical unconventional reservoir, a coal reservoir is dominated by nanopores, and its permeability exhibits strong sensitivity. No detailed research has been conducted on how a foreign fluid damages the nanopores in a coal reservoir when the fluid intrudes. This lack of research is also one reason that coal reservoir damage remains unsolved though many theoretical studies have been performed on macrocoal reservoir damage evaluation.

This study examined coal samples from the Anze coalbed methane area in the North China Oilfield to address this gap. First, the experimental materials are presented. Second, the mineral composition of the test coal was analysed. Third, the experimental instruments and methods were introduced. Fourth, the damage evaluation experiment of coal sample permeability under different working fluid concentration was carried out. Moreover, the damage evaluation experiment of coal sample permeability under different working fluid concentration was carried out. Finally, the reasons of permeability reduction caused by nanopore plugging were found.

Therefore, a damage rate experiment was conducted on nanopore permeability by using the pressure oscillation method, and the nanopore characteristics of coal samples after pollution were observed via scanning electron microscopy (SEM). With a large number of experimental results, the laws of nanopore plugging and permeability reduction were explored, the main factors that affect the permeability of coal reservoirs were determined, and drill fluid systems for lowporosity, low-permeability coal reservoirs were optimized.

\section{Experimental Materials}

\subsection{Microanalysis of Test Samples and Mineral Components}

2.1.1. Test Samples. The Anze coalbed methane block of the Huabei Oilfield is located in the southwest part of the 
Qinshui Basin, with a horseshoe-shaped slope as its general structural form. An uplift area exists in the east, west, and south directions, and an arc-shaped fault zone composed of a group of new normal faults exists in the east. A few faults are present in the area, and several small structures are developed.

This study adopted the Anxin Mine in the Anze block as the target sampling area. Raw coal was selected randomly from the same block for the experimental study. Each sample was dried at $80^{\circ} \mathrm{C}$ in a vacuum condition, and the composition of each group of samples was considered similar. The samples are shown in Figure 1. A standard test core with a diameter of $25 \mathrm{~mm}$ and length of $50 \mathrm{~mm}$ was created and used for the subsequent permeability test on the coal reservoir.

In Figure 1, A1-A7 coal samples are used for "damage evaluation of the permeability of coal samples under different fluid concentrations." B1-B6 coal samples are used for the "analysis of the damage degree of pressure difference on the coal reservoir." D1-D5 coal samples are used for the "analysis of the mineral composition and pore structure of the working samples."

\subsubsection{Analysis of the Mineral Composition and Pore Structure} of the Test Coal. The mineral composition is a factor that affects permeability [42-44]. The entire rock and clay minerals of the coal samples were analysed through X-ray diffraction. Mineral analysis of the whole rock showed that the minerals in the coal seam of the Anxin Mine in the Anze area were mainly quartz, calcite, and dolomite. Quartz was the most important brittle mineral with a mass fraction of $0.9 \%-13.2 \%$, the calcite mass fraction was $1.0 \%$ on the average, and the dolomite mass fraction was $0.77 \%$ on the average. The average content of clay minerals was $15 \%-32 \%$. The clay minerals accounted for a large proportion (Table 1).

The analysis of clay minerals showed that the main types included illite (I), kaolinite (k), chlorite (c), and I/s, which accounted for $8.2 \%, 45.8 \%, 15.4 \%$, and $40 \%$, respectively. The different clay minerals seriously affected the characteristics and permeability of coal (Table 2).

X-ray diffraction revealed that the fracture of the test sample was developed and contained nanopores (Figures 2(a) and 2(c)). The pore diameter was between 20 and $2 \mu \mathrm{M}$. Nanoparticles (Figures 2(b) and 2(d)) were attached to the surface. The pore size of different types of clay minerals was different, and the morphology was mainly lamellar, filiform, scaly, and honeycomb (Figures 2(e) and 2(f)). The fracture fillings were illite with a small amount of montmorillonite and illite mixed layer, which were attached to the surface of the coal sample and had loose cementation. The fracture pore had good connectivity. Once the working fluid flowed into the pore, the clay minerals and other particles filled in the pore fracture and hydrated it. Consequently, the pore throat was blocked, and serious damage was exerted on the coalbed methane reservoir.

The kaolinite in the clay minerals was in the form of a pseudohexagonal plate and vermicular, mostly in the form of thin slices deposited in the pores (Figures $2(\mathrm{~g})$ and $2(\mathrm{~h})$ ). The book-like structure in the foreign fluid slid along the small sheet. It could easily fall off the original structure and move with the foreign fluid. Clay minerals illite, chlorite, and illite mixed layer are curved and batty. They easily expand when encountering water, thereby falling off and blocking the coal nanopores.

2.2. Evaluation and Test Fluids. In accordance with the evaluation of coal sample pollution with the main single-agent fluid in the field, the single agents selected were distilled water, $\mathrm{KCl}$ fluid with different concentrations, and DPC water-soluble polymer fluid with different concentrations (Figure 3). The apparent viscosity of the DPC water-soluble polymer was significantly higher than that of distilled water and the $\mathrm{KCl}$ solution (Table 3 ). DPC is a highly molecular water-soluble polymer. The molecular weight is $1,000,000$ and the molecular formula is $\left(\mathrm{C}_{35} \mathrm{H}_{49} \mathrm{O}_{29}\right)_{n}$ (Figure 4). The polymer molecular chain has a cation group and an anion group, which has a good viscosity-increasing effect, can effectively inhibit the hydration expansion of coal and rock, and can effectively stabilise the well wall.

\section{Main Experimental Methods}

(I) Microstructure analysis. The main experimental instrument was a Supra55 scanning electron microscope from the Zeiss Company in Germany. The core micromorphology was observed using the scanning electron microscope at a magnification of $10,000 \mathrm{x}$ and a resolution of about $1 \mathrm{~nm}$

(II) Whole rock mineral analysis and clay mineral relative content determination. The whole rock mineral analysis and the relative content determination of the clay mineral of coal were carried out using a Japanese Physico-d/MAX $2500 \mathrm{X}$-ray diffractometer

(III) Permeability test. Darcy's law is usually used to test permeability. However, determining the value of the classic Darcy's law quantitatively is difficult for a reservoir with small pore medium gap and is difficult in the passing fluid. In this experiment, a JZXGP-II wide-spectrum intelligent gas permeability tester based on the pressure oscillation method was selected for an ultralow permeability test. The classic Darcy's law test method was combined with the pore pressure oscillation method. When the core permeability could not be measured under linear pressure, the curve sine wave was used to pass through the core to quantitatively test the ultralow permeability of the core

Test methods: first, the confining pressure was adjusted to 2.0 MPa. The presence of an air leakage was checked, and the confining pressure was slowly adjusted to $5 \mathrm{MPa}$ (while still checking for air leakage). Then, the pressure is released. Second, the enclosure was raised to the preset value. Third, the permeability of the coal sample was measured before pollution. The sine pump was initialised, and the test began. A stable waveform indicated that the pressure was balanced. At least one complete sine wave period was collected before 


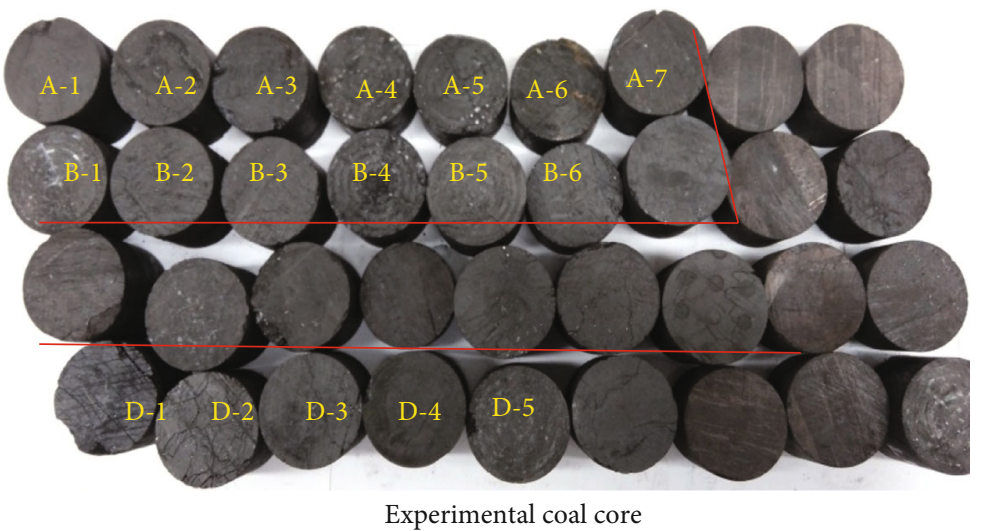

Figure 1: Experimental coal sample.

TABLE 1: Rock mineral analysis.

\begin{tabular}{lcccccccc}
\hline \multirow{2}{*}{ Serial number } & \multirow{2}{*}{ Sample name } & \multicolumn{4}{c}{ Mineral type and content (\%) } & \multicolumn{2}{c}{ Total amount of clay minerals (\%) } \\
& & Quartz & Soda feldspar & Calcite & Dolomite & Pyrite & Amorphous & 24.3 \\
2 & D-1 & 8.5 & 1.4 & 0.3 & - & 1.0 & 64.5 & 32.0 \\
3 & D-2 & 13.2 & 1.7 & 0.7 & 1.2 & 0.7 & 50.5 & 15.3 \\
4 & D-3 & 2.1 & - & 2.0 & - & - & 80.6 & 18.8 \\
5 & D-4 & 0.9 & - & 1.3 & 0.3 & - & 88.7 & 18.2 \\
\hline
\end{tabular}

TABLE 2: Clay mineral analysis.

\begin{tabular}{|c|c|c|c|c|c|c|c|}
\hline \multirow{2}{*}{$\begin{array}{l}\text { Serial } \\
\text { number }\end{array}$} & \multirow{2}{*}{$\begin{array}{c}\text { Sample } \\
\text { name }\end{array}$} & \multicolumn{5}{|c|}{$\begin{array}{l}\text { Relative content of } \\
\text { clay minerals (\%) }\end{array}$} & \multirow{2}{*}{$\begin{array}{c}\text { Mixed layer ratio } \\
(\% \mathrm{~S}) \\
\mathrm{I} / \mathrm{S} \\
\end{array}$} \\
\hline & & $S$ & $\mathrm{I} / \mathrm{S}$ & I & $\mathrm{K}$ & $\mathrm{C}$ & \\
\hline 1 & D-1 & - & 67 & 13 & 14 & 6 & 25 \\
\hline 2 & D-2 & - & 36 & 8 & 41 & 15 & 30 \\
\hline 3 & D-3 & - & 24 & 5 & 55 & 16 & 20 \\
\hline 4 & D-4 & - & 14 & 6 & 50 & 30 & 75 \\
\hline 5 & D-5 & - & 12 & 9 & 69 & 10 & 50 \\
\hline
\end{tabular}

the experiment was stopped. The permeability of the coal sample before pollution was determined to be $K_{o}$. Fourth, coal pollution permeability was determined. Under the condition of constant confining pressure, the pollution differential pressure was detected and the circulating pump was initialised until the working fluid contaminated the core to the set time and the circulating pump was closed. The determination procedure (Step 3) was repeated until the permeability of the coal sample polluted by the foreign working fluid was $K_{d}$. Lastly, the permeability damage rate of the coal sample was calculated as $D_{d}=\left(K_{o}-K_{d}\right) / K_{o} \times$ $100 \%$.

(IV) Particle size distribution of the nanoparticles in polluted solution. The average geometrical particle size of the working fluid carried by the polluted core was measured using a Winner801 nanolaser reflection particle size distribution analyser, and the cumulative particle size distribution of the working fluid and solid phase was determined

\section{Results and Discussion}

4.1. Damage Evaluation of the Permeability of Coal Samples under Different Fluid Concentrations. Permeability damage rate is a direct indication of the permeability damage degree. Although fully reflecting the factors that cause permeability reduction is difficult, the damage degree of the coal sample polluted by the working fluid can be analysed well.

There are many methods to study the damage of a coal seam reservoir $[21,22]$. At present, the main methods are water sensitivity and stress sensitivity methods [24, 25]. For the water-sensitive damage, the current research usually considers that the formation permeability damage is caused by the hydration and expansion of clay minerals when they meet with water $[3,4,9,10]$. However, the current research does not consider the damage of fluid concentration and action time to the reservoir. In fact, the hardness of reservoir damage caused by fluid concentration and action time cannot be ignored. Therefore, the damage evaluation of coal permeability under different fluid concentrations is carried out.

In accordance with the three kinds of single fluid prepared previously, distilled water; $\mathrm{KCl}$ with a concentration of $1 \%, 3 \%$, and $5 \%$; and DPC working fluid with a concentration of $0.1 \%, 0.2 \%$, and $0.3 \%$ were configured to test the influence of different concentrations of fluid on coal reservoir permeability. The core contamination pressure difference was set to $2 \mathrm{MPa}$ in the experiment.

4.1.1. Evaluation of the Damage of Distilled Water on Coal Permeability. It is generally believed that distilled water does not cause the action of minerals in coal, because even if there are active groups on the surface of coal, it is difficult for 


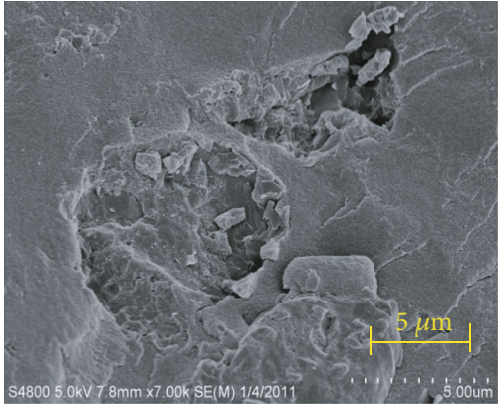

(a)

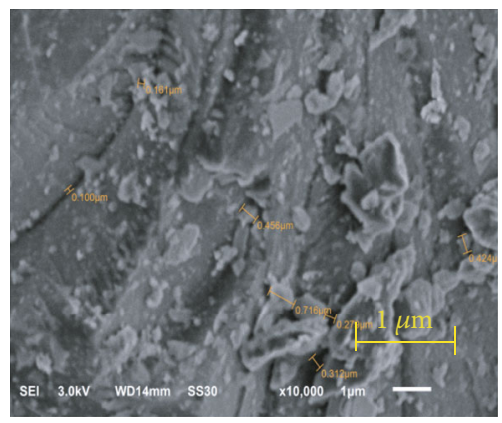

(c)

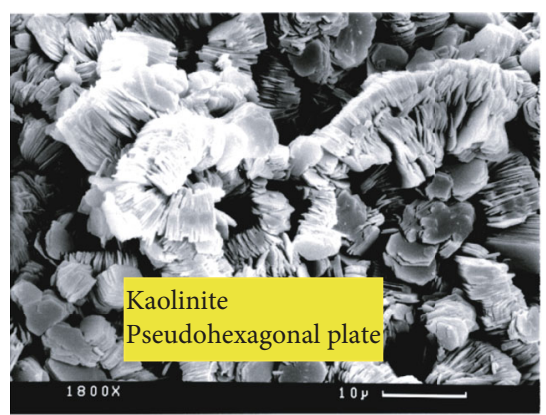

(e)

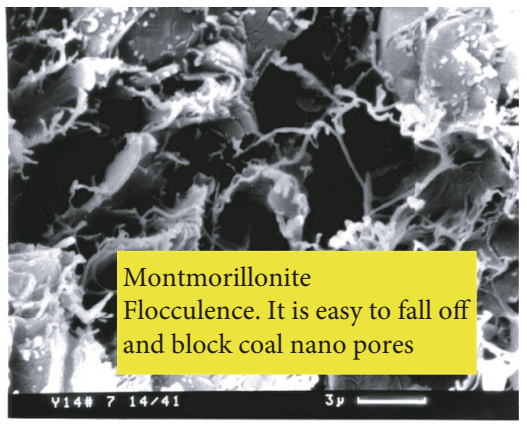

(g)

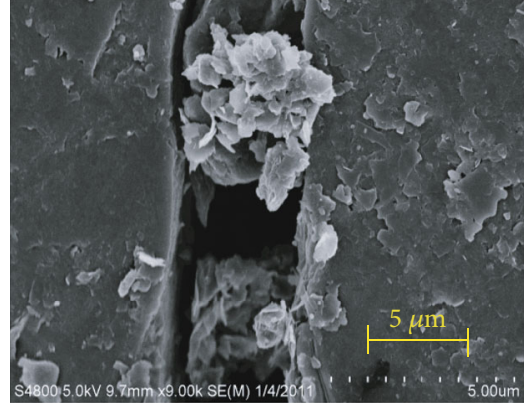

(b)

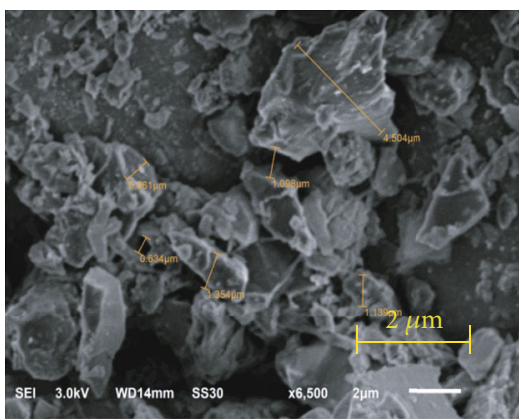

(d)

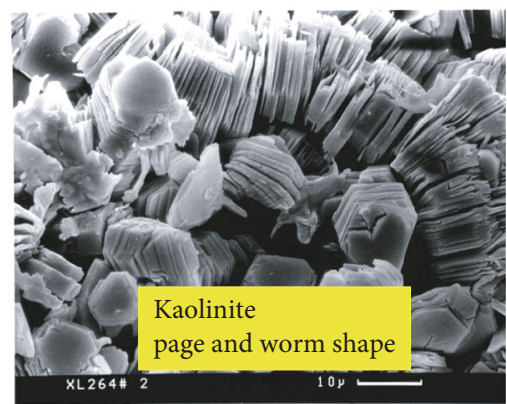

(f)

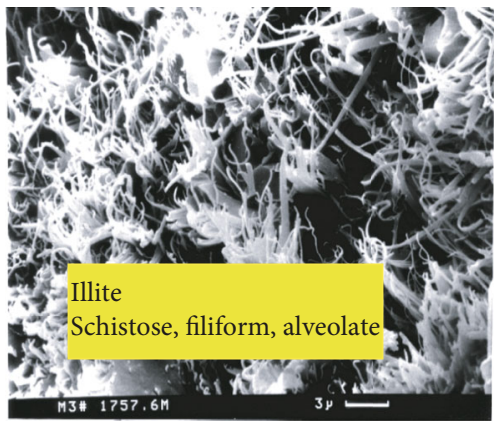

(h)

FIGURE 2: Electron microscope images of the coal microstructure.

distilled water to react with it. Therefore, damage experiments on the coal reservoir were conducted with distilled water.

The coal samples were tested for permeability and permeability damage with distilled water for $150 \mathrm{~h}$. The test results showed that the damage rate of permeability was $20.98 \%$ and $40.52 \%$ after 28 and $45 \mathrm{~h}$ of distilled water pollution, respectively. The damage rate of permeability changed to $89.01 \%$ after $116 \mathrm{~h}$ of pollution. The damage rate of permeability was $91.62 \%$ and $92.63 \%$ after 123 and 148 h of pollution, respectively, and tended to be stable (Figure 5(a)).

The rapid increase in the permeability damage rate was due to two factors. The first is that distilled water easily invades the coal seam under the condition of positive pressure difference drilling, which causes the hydration and expansion of clay minerals in the coal seam. Within $116 \mathrm{~h}$ 


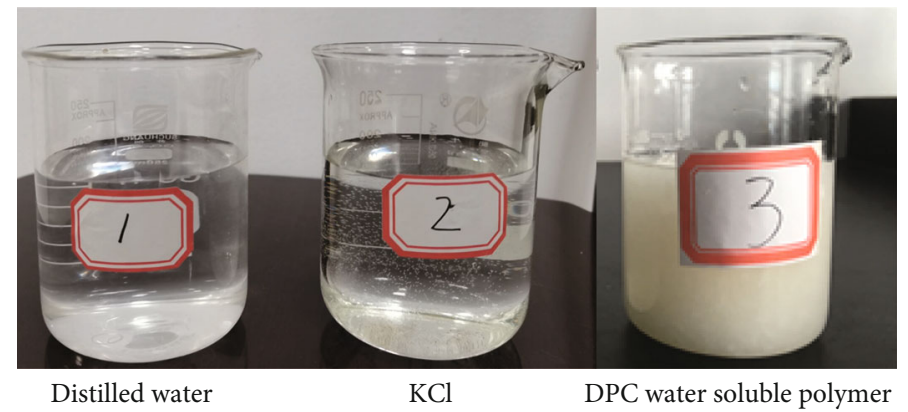

FIGURE 3: Working fluids.

TABLE 3: Basic features of the working fluids.

\begin{tabular}{lcccc}
\hline $\begin{array}{l}\text { Fluid } \\
\text { number }\end{array}$ & Fluid type & $\begin{array}{c}\text { Density } \\
\left(\mathrm{g} / \mathrm{cm}^{3}\right)\end{array}$ & $\begin{array}{c}\text { Apparent viscosity } \\
(\mathrm{mPa} \cdot \mathrm{s})\end{array}$ & $\mathrm{pH}$ \\
\hline 1 & $\begin{array}{c}\text { Distilled } \\
\text { water }\end{array}$ & 1.00 & 1.00 & 6.5 \\
& $1 \% \mathrm{KCl}$ & 1.00 & 1.00 & \\
2 & $3 \% \mathrm{KCl}$ & 1.03 & 1.03 & 7.0 \\
& $5 \% \mathrm{KCl}$ & 1.04 & 1.10 & \\
& $0.1 \% \mathrm{DPC}$ & & 3.30 & \\
& $0.3 \% \mathrm{DPC}$ & 1.04 & 8.50 & 7.6 \\
& $0.5 \% \mathrm{DPC}$ & & 17.00 & \\
\hline
\end{tabular}

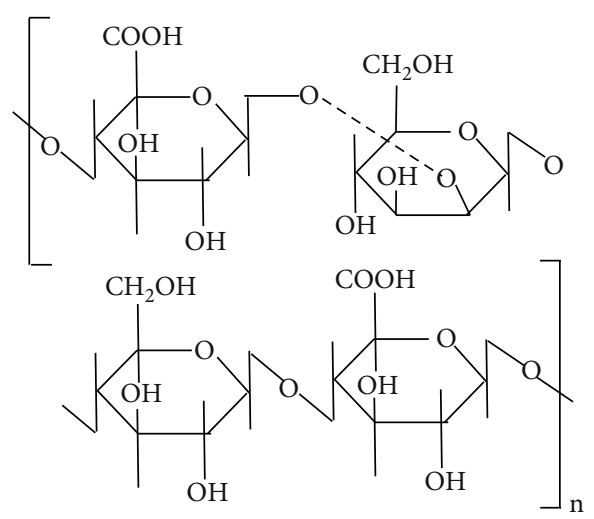

FIgURE 4: Molecular structure of DPC.

of pollution, the coal samples were mainly hydrophobic. With the increase in pollution time, namely, after $116 \mathrm{~h}$ of pollution, the specific water absorption of the porous rock dominated, the water absorption was enhanced, and the pores decreased. Thus, the degree of coal reservoir pollution increased rapidly. The second factor is that with the increase in pollution time, the clay mineral particles fell off, and water carried these nanoparticles into the nanopores, thereby blocking the pores and resulting in a decrease in permeability.

The expansibility of the coal particles was tested to verify the two conjectures. The coal particles with a particle size of about $45 \mu \mathrm{m}$ were placed in a glass container tube. The coal particles are soaked with the three fluids prepared previously (Figure 6). During the soaking process, a certain amount of coal particles was discharged every other period to test the particle size change.

Figure 7 shows the change curve of coal ash particle size with soaking time. After soaking in distilled water, the particle size of coal ash increased, decreased, and then increased because the clay mineral in the coal reservoir absorbed distilled water, which caused the volume of coal to increase. The clay in the coal particle expanded to a certain volume and collapsed, thus causing the particle size to decrease. The pore in the cracked coal particle reabsorbed the liquid phase, which caused the volume of the coal particle to increase. These results show that the water swelling of clay minerals is an important factor that causes permeability to decrease.

After soaking in the $\mathrm{KCl}$ working solution, the particle size of coal ash increased, decreased, and then stabilised. $\mathrm{KCl}$ exerted a certain inhibitory effect on the clay minerals because in the stage of the crystal layer expansion of clay, the cations between layers are bound and cannot carry out ion exchange; hence, $\mathrm{K}^{+}$cannot effectively inhibit the crystal layer expansion of $\mathrm{Na}$ montmorillonite and $\mathrm{Ca}$ montmorillonite. In the stage of permeability and expansion of clay and completely dispersed clay, interlayer cations can exchange ions and $\mathrm{K}^{+}$can effectively inhibit the permeability, expansion, and dispersion of clay.

DPC had a good inhibiting effect on the expansion of coal particles. After soaking for $195 \mathrm{~h}$, the geometric average particle size was maintained at about $45 \mu \mathrm{m}$, which shows that the DPC fluid had a good effect on keeping the volume of coal particles unchanged. DPC formed a diaphragm on the surface of the coal sample. As a result, the water in the working fluid could not easily come into contact with the coal sample further, thus inhibiting the expansion of clay particles.

Permeability change is the macroscopic performance of rock porosity and pore structure. The current research thinks that the damage of water sensitivity is mainly caused by the hydration/expansion of water sensitive clay [27-30]. But our research shows that the hydration expansion has a certain time limit, the hydration expansion effect is not obvious in a short time, and the effect of reducing permeability is obvious after a long time.

4.1.2. Evaluation of the Damage of Different $\mathrm{KCl}$ Concentrations on Coal Permeability. $\mathrm{KCl}$ has a good 


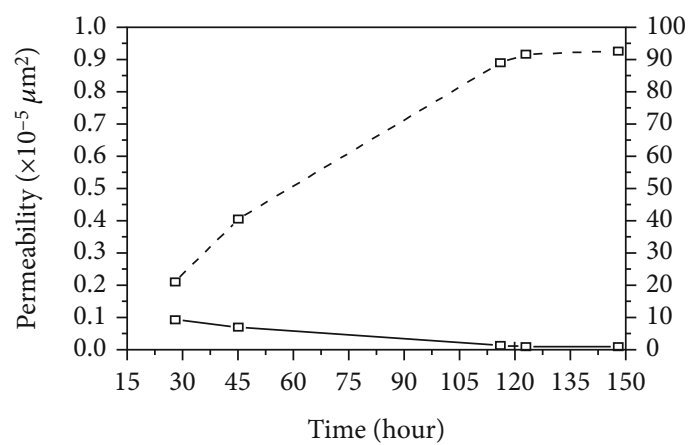

$\rightarrow-$ Permeability of distilled water - - - Damage rate of distilled water

(a) Distilled water

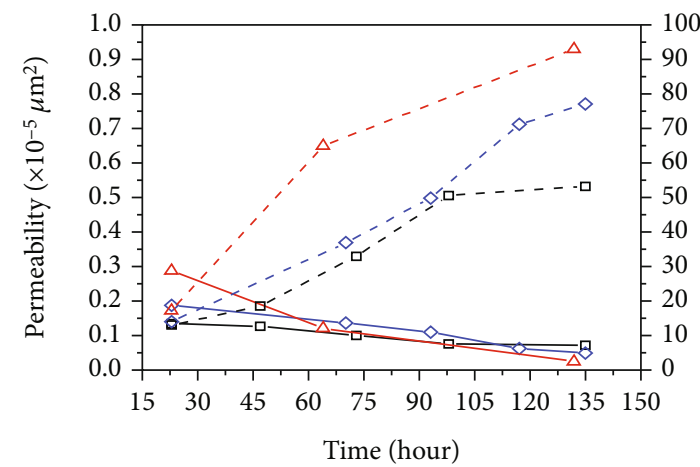

$\neg-$ Permeability of $0.1 \% \mathrm{KC} 1$

$\checkmark$ Permeability of $0.3 \% \mathrm{KC} 1$

$\triangle-$ Permeability of $0.5 \% \mathrm{KC} 1$

- - Damage rate of $0.1 \% \mathrm{KC} 1$

$-\diamond-$ Damage rate of $0.3 \% \mathrm{KC} 1$

$-\Delta-$ Damage rate of $0.5 \% \mathrm{KC} 1$

(c) DPC

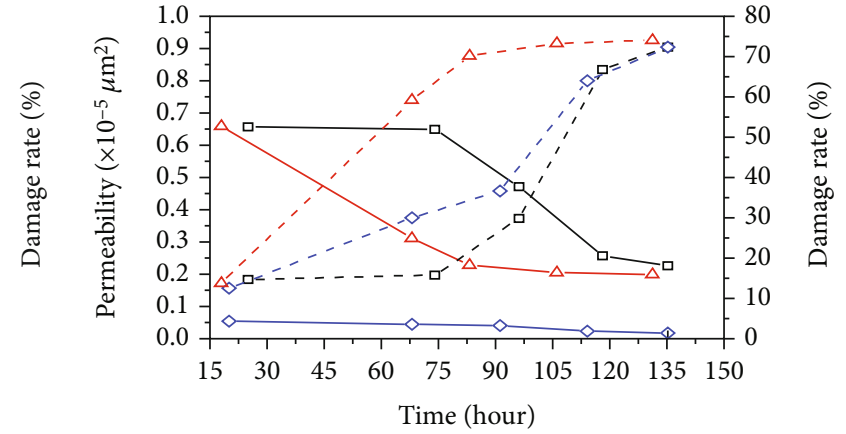

$\neg-$ Permeability of $1 \% \mathrm{KC} 1$

$\checkmark$ Permeability of $3 \% \mathrm{KC} 1$

$\triangle-$ Permeability of $5 \% \mathrm{KC} 1$

$-\square-$ Damage rate of $1 \% \mathrm{KC} 1$

$-\diamond-$ Damage rate of $3 \% \mathrm{KC} 1$

$-\Delta-$ Damage rate of $5 \% \mathrm{KC} 1$

(b) $\mathrm{KCl}$

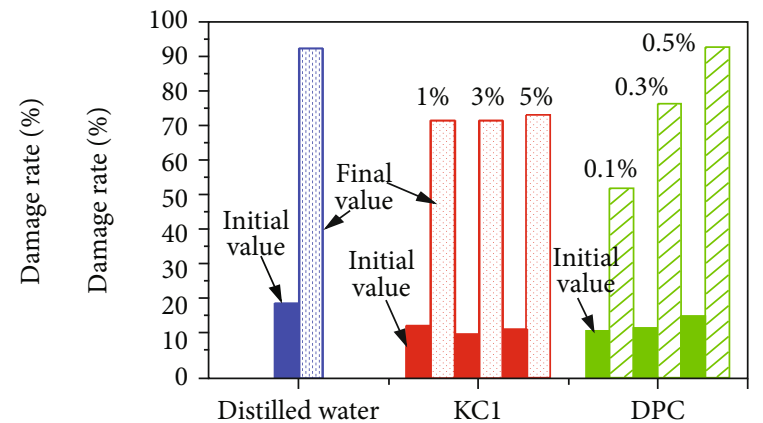

FIgURE 5: Evaluation of the damage of different fluids on coal reservoir permeability.

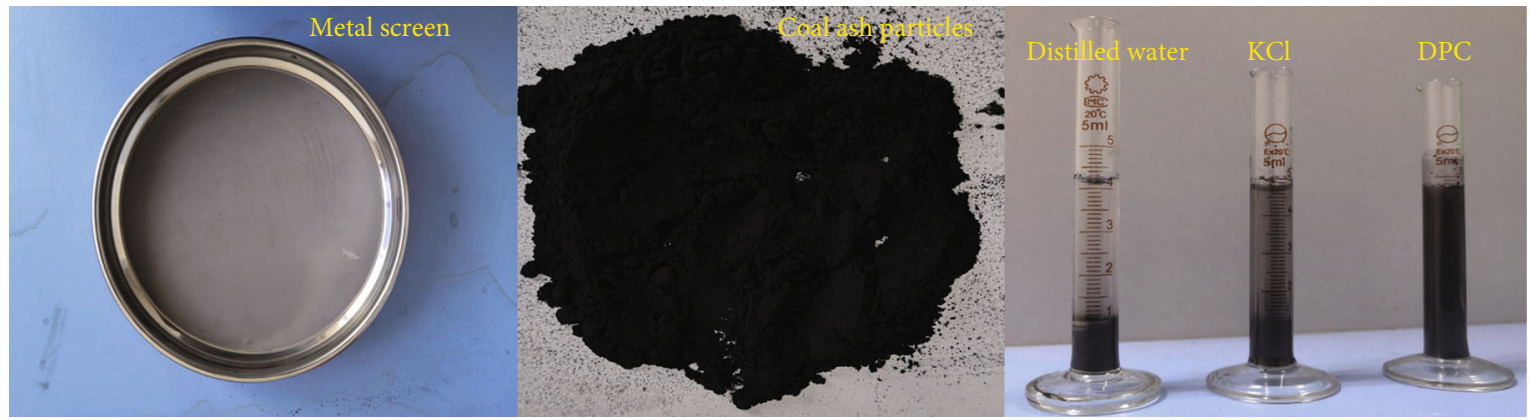

FIGURE 6: Test on coal ash particle expansion with different fluids.

swelling inhibition effect on clay minerals in coal. However, $\mathrm{KCl}$ cannot easily restrain the microexpansion of clay minerals. Under the same $2 \mathrm{MPa}$ pollution pressure difference,
$\mathrm{KCl}$-polluted coal samples at different concentrations were used to further analyse the relationship between concentration and pollution degree. 


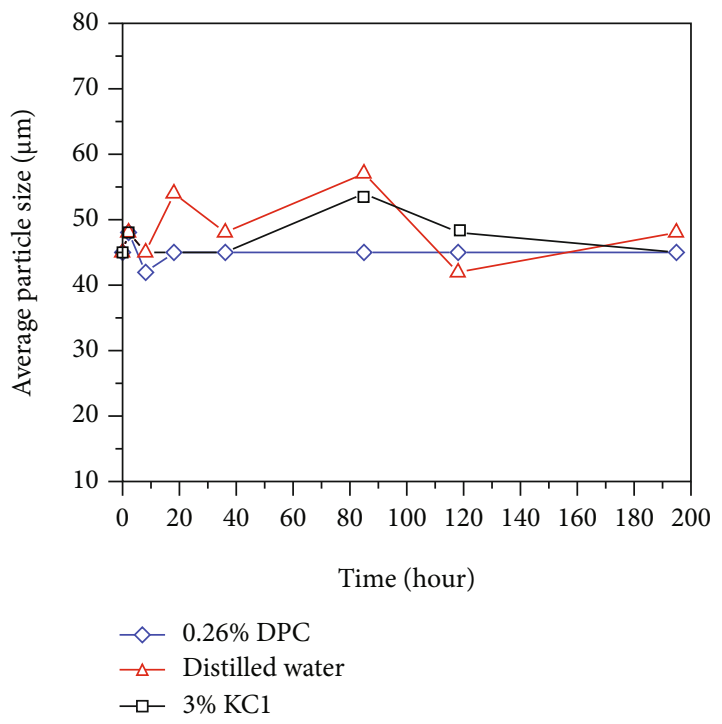

FIGURE 7: Geometric mean diameter change in the coal ash particles under different working liquids.

According to the evaluation of the permeability damage of the coal reservoir with different concentrations of $\mathrm{KCl}$ (Figure 5(b)), for $1 \% \mathrm{KCl}$, that is, a certain hydrophobicity remained within $118 \mathrm{~h}$. After more than $118 \mathrm{~h}$, the water absorption damage of porosity was dominant and caused particle expansion. The damage degree of permeability increased rapidly. This time point is similar to that of distilled water. For $3 \% \mathrm{KCl}$, These data show that the damage rate of coal permeability increases significantly after $114 \mathrm{~h}$ of pollution, which is consistent with the data for $3 \%$ and $1 \% \mathrm{KCl}$. For $5 \% \mathrm{KCl}$, evidently, $68 \mathrm{~h}$ after $5 \% \mathrm{KCl}$ and $114 \mathrm{~h}$ after $3 \% \mathrm{KCl}$ reached the mutation injury rate, the amount of time was reduced considerably. The higher the concentration was, the higher the injury rate was.

The higher the concentration of $\mathrm{KCl}$ was, the stronger the inhibition of the hydration and expansion of clay mineral components in coal was. The permeability of the coal sample should be increased. However, the test results showed that the permeability of the coal sample decreased. We speculate that the main reason for this phenomenon was the flow and erosion of coal ash nanoparticles carried by $\mathrm{KCl}$, which caused the nanoparticles to block the nanopores. The damage rate of permeability therefore increased.

4.1.3. Evaluation of the Damage of Different DPC Concentrations on Coal Permeability. DPC has a good inhibition effect on the expansion of coal particles, and the geometric average particle size remains the same for a long time. The damage degree of the DPC working fluid with different concentrations on coal permeability was analysed. The influence of the working fluid on the permeability damage of the coal sample under the influence of nonexpansion factors was clarified.

At $2 \mathrm{MPa}$ pollution differential pressure, coal samples were polluted with DPC at different concentrations (Figure 5(c)). The permeability damage rates of $0.1 \%$ DPC working fluid in $23,47,73,98$, and $135 \mathrm{~h}$ were $13.16 \%$, $18.56 \%, 33.02 \%, 50.65 \%$, and $53.26 \%$, respectively. The permeability damage rates of $0.3 \%$ DPC working fluid in 70 , 93,117 , and $135 \mathrm{~h}$ were $37.01 \%, 49.73 \%, 60.64 \%$, and $77.03 \%$, respectively. The permeability damage rates of $0.5 \%$ DPC working fluid in 16,64 , and $132 \mathrm{~h}$ were $31.67 \%$, $65.023 \%$, and $93.01 \%$, respectively. The permeability damage rates of the three concentrations of working fluid changed in a straight line, and the greater the ion concentration was, the higher the damage rate was. The influence of clay mineral expansion on permeability was excluded. The damage rate of the DPC working fluid with a high concentration was low because the working fluid intruded into the cementation edge of the coal ash nanoparticles and matrix and destroyed the cementation between them. The migration of coal ash nanoparticles blocked the nanopores of the reservoir, resulting in increased permeability damage concentration, increased viscosity, and increased damage to the coal reservoir.

A comparison of the initial and final damage rates (Figure 5(d)) of different concentrations of the working fluid revealed that although the concentration of $\mathrm{KCl}$ varied, the final damage rate was the same because $\mathrm{KCl}$ could effectively inhibit the expansion of clay particles. Although the concentration varied, the viscosity remained the same and low, so nanoparticles were not easily carried away, and the final injury rate was the same. The damage of distilled water on the coal reservoir was mainly expansibility. The viscosity of the DPC solution at $0.1 \%, 0.3 \%$, and $0.5 \%$ was $3.30,8.5$, and $17 \mathrm{mPa} \cdot \mathrm{s}$, respectively. The permeability damage rate was the lowest at a low viscosity. In the case of high viscosity, the permeability damage rate was the highest. DPC could effectively restrain particle expansion, and only the nanoparticle carried by scour could block the pores and reduce permeability. Therefore, the higher the viscosity was, the easier it was to carry nanoparticles and the greater the permeability damage rate was. A comparison of $0.3 \%$ and $0.5 \%$ viscosity showed that the initial injury rate was the same, but the final injury rate increased from 77.03 to 99.7. The viscosity increased by two times, and the damage rate increased by 1.21 times. The permeability of the reservoir was seriously affected.

Previous studies only noted that the hydration expansion of coal clay minerals is the fundamental cause of water sensitivity damage of coal reservoir. Particle dispersion and migration is not the main cause of damage [35]. Through this experiment, we find that not only hydration expansion but also particle dispersion and migration have a great influence on permeability. It is related to the viscosity of the fluid. The higher the fluid viscosity is, the more likely the particle migration is. The damage rate of permeability is greater. This is not recognized by previous studies.

4.2. The Effects of Single Working Fluid Concentration on Nanopore Plugging. We can only infer from the macroperspective that the reason for the permeability reduction of the coal sample is the blockage of coal ash nanoparticles, which cannot represent the influence of nanopores on permeability. To truly understand the possibility of nanoparticle 
plugging, the micromorphology analyses of coal samples before and after pollution must be combined.

Through a comparative analysis of the microstructure of raw coal samples not polluted by the working fluid and the microstructure of coal samples after being polluted by the working fluid, we found that the surface of raw coal was flat with nanoparticles attached, and abundant nanoholes were present (Figures 8(a)-8(d)). These holes provide the possibility for the invasion of foreign fluid and the blockage of nanoparticles. Once the nanoparticles block the pores, permeability will decrease.

After being polluted by distilled water, $\mathrm{KCl}$, and DPC working fluids, the morphology of coal samples was observed under different magnifications of the electron microscope. The samples had obvious erosion traces (Figures $8(\mathrm{e})-8(\mathrm{~h})$ ), and a large number of nanoparticles moved with the fluid, resulting in the accumulation of microparticles and plugging of microcracks (Figures 8(i)-8(l)). Nanoparticles with different sizes were embedded in the fractures and pores with fluid flow, thus plugging the fractures and pores (Figures 8(m)$8(\mathrm{p})$ ), polluting the coal samples, and affecting the permeability of the coal reservoir.

The clay in the coal sample was mostly deposited in the pores as thin slices. After washing with an external working fluid, the cation existing in the formation water may have been destroyed, and the negative charge on the surface of the clay slice was maintained to keep the balance of electric neutrality, resulting in the dispersion of the clay slice. In addition, particles were observed in the bound water near the pores of the hydrophilic formation. If the water intrudes into the mobile water phase, these particles will disperse and participate in the migration. Particle migration eventually leads to a particle bridge, thus plugging the pore throat and reducing the formation permeability.

The existing research on the influence of particle migration on permeability can only speculate that the solid particles in coal enter into the fracture and pore throat of reservoir with fluid flow, block the flow channel of coalbed methane, and reduce the permeability. But there is no direct evidence $[3,6,15]$. In this paper, through a comparative analysis of the microstructure of raw coal samples not polluted by the working fluid and the microstructure of coal samples after being polluted by the working fluid, it was found that when the fluid flows, the particles are affected by the viscous force, and the particles in coal easily migrate together with the fluid, which seriously affects the permeability.

\subsection{Analysis of the Damage Degree of Pollution Pressure} Difference on the Coal Reservoir. Given that the nanoparticles in the coal ash move with the working fluid, the pores become blocked. Thus, the situation of migration and blockage varies with different pollution pressure differences. This condition means that the damage degree of coal samples differs under different scour forces. The pollution pressure difference is the difference between the drilling fluid column pressure and the formation pore pressure.

A damage rate test of the permeability of the working fluid with different ion concentrations was conducted under $2 \mathrm{MPa}$ pollution differential pressure. The pollution differen- tial pressure was increased to $4 \mathrm{MPa}$, and the change in the pollution degree of coal samples under different pollution differential pressures was investigated. The maximum damage rate of permeability increased from $92.63 \%$ to $97.9 \%$, and the damage rate of permeability increased steadily (Figure 9(a)). The damage rate of permeability at $4 \mathrm{MPa}$ was slightly higher than that at $2 \mathrm{MPa}$. However, the difference was small.

Generally, $3 \% \mathrm{KCl}$ is the most frequently used concentration. We replaced the medium with $3 \% \mathrm{KCl}$ working fluid and compared the influence of the pollution pressure difference on coal permeability under 4 and $2 \mathrm{MPa}$. Permeability continued to decrease under the pressure difference of $2 \mathrm{MPa}$. However, under the action of $4 \mathrm{MPa}$ pressure difference, the permeability of the coal sample increased with the increase in time. After a certain period, the permeability dropped sharply, and the trend stabilised after reaching the maximum value (Figure 9(b)). Owing to the increase in the pressure difference, the working fluid washed out the nanoparticles in the coal sample under the action of a certain continuous pressure difference, resulting in the increase in permeability. During the washing process, the nanoparticles gradually migrated and accumulated, thereby blocking the pores. The permeability decreased with the increase in time. The permeability was two orders of magnitude lower than the initial permeability.

The experiment on the permeability change of the coal sample under the action of $0.3 \%$ DPC working fluid further verified the influence of particle migration and blockage of the pollution differential pressure on permeability. Under different pollution pressure differences, the change trend of coal permeability under the action of $0.3 \%$ DPC working fluid was similar to that of $3 \% \mathrm{KCl}$. Permeability decreased continuously under $2 \mathrm{MPa}$ pressure difference. However, under the action of $4 \mathrm{MPa}$ pressure difference, with the increase in pollution time, the coal powder washed out the coal sample with the fluid, and some coal powder was probably washed out too; this improved the permeability condition and made the permeability of the coal sample increase instead. When the pollution reached $62 \mathrm{~h}$, the damage rate of permeability reached the minimum value. With the increase in time, the solid particles or other impurities in the polluted liquid were washed away in a short time to improve permeability (Figure 9(c)). Then, with the increase in pollution time, the coal powder continuously polluted the coal sample, permeability decreased almost linearly, and the permeability damage rate reached the maximum value.

Under the $4 \mathrm{MPa}$ pressure difference, the damage rate of the final permeability of the three kinds of fluids exceeded $90 \%$, and no significant difference was observed. However, the change in permeability in the observation period showed that the final permeability generally decreased by three orders of magnitude compared with the initial permeability (Figure 9(d)). No gas was recovered anymore.

The process of nanoparticle expansion, sliding, plugging, migration, and plugging in pores, is shown in Figure 10. With this process, the permeability decreases and increases and then reaches the minimum value. 


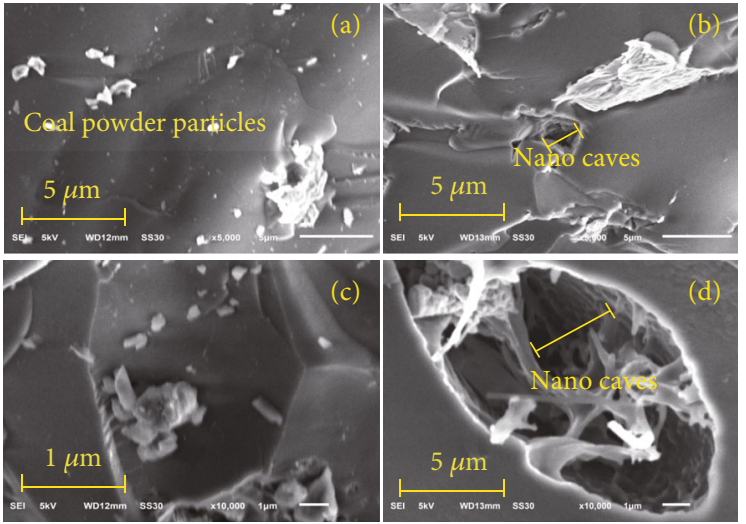

Raw coal

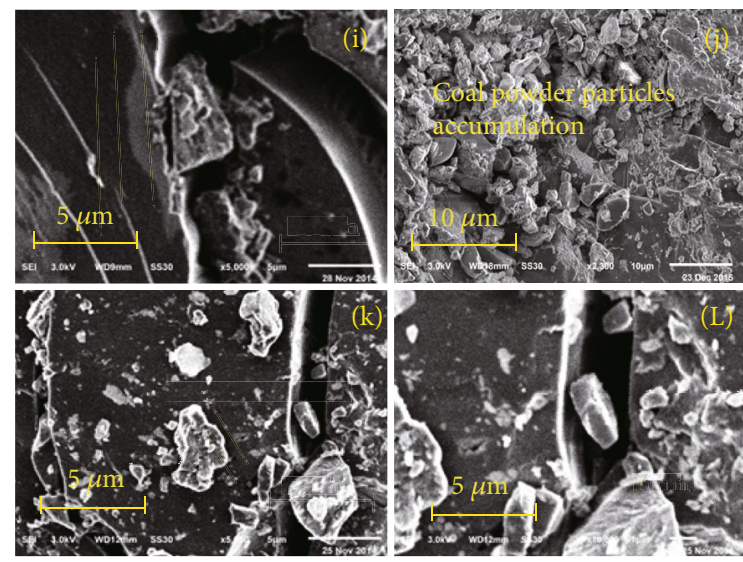

Polluted by $3 \% \mathrm{KCl}$

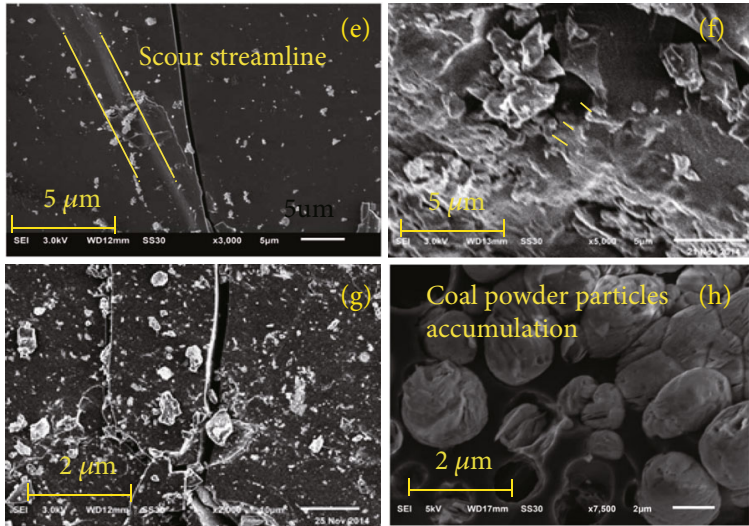

Polluted by distilled water

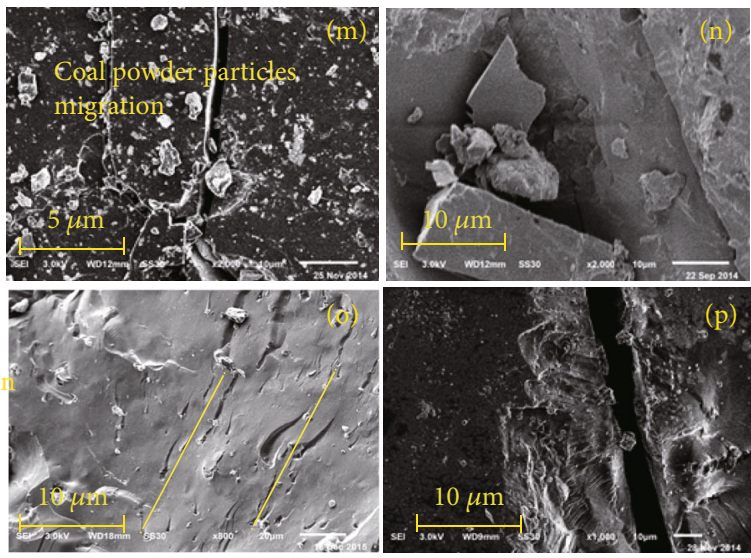

Polluted by $0.3 \%$ DPC

Figure 8: Micromorphology of raw coal core and polluted coal samples.

The stress sensitivity study only noticed that the greater the axial confining pressure is, the more serious the permeability damage is. It was not observed that the increase of radial flow pressure difference (pollution pressure difference) will affect the permeability [24, 25]. It is found that the permeability fluctuates with the increase of pollution pressure difference. Because the fluid drives the particle migration, the pore channel increases and the permeability increases, and then, the particles plug the pores and reduce the permeability. Reasonable control of pollution pressure difference is particularly important for increasing permeability.

\subsection{The Effects of Pollution Pressure Difference on Nanopore} Plugging. With the increase in scour force, the small particles in the coal sample moved under the action of such force, leading to different permeability changes. Permeability decreased with the increase in pollution time. The damage of the scour force on the coal reservoir can be further verified through SEM.

The coal samples polluted by distilled water, $\mathrm{KCl}$, and DPC working fluids were selected as the observation objects. The microelectron microscope image taken after the core was cut showed traces of erosion on the surface of the rock sample (Figures 11(a), 11(b), 11(c), 11(h), 11(i), 11(l), and 11(m)) accompanied with the migration of nanoparticles. This phenomenon further indicates that under a certain pressure dif- ference, the working fluid entered into the dense core along with the fluid entering the coal sample for flushing (Figures 11(f), 11(k), and 11(o)). The fluid caused damage to the pores of the coal reservoir. When several small pores were flushed, the permeability of the coal sample increased. New small particles moved with the fluid entering the coal matrix or the small particles in the coal matrix. This situation caused damage on the coal reservoir (Figures 11(d), 11(e), $11(\mathrm{j})$, and 11(n)).

If the fluid is continuously washed out, the coal sample will be continuously polluted, different fluids will be continuously washed out, and nanoparticles will continuously enter the reservoir with the fluid, thus causing damage to the coal reservoir. In the process of onsite construction, the smaller the amount of fluid entering the coal reservoir is, the better and faster the construction is.

In Figure 2, the nanopores of the coal samples are dispersed between $20 \mathrm{~nm}$ and $3 \mu \mathrm{m}$. The system of distilled water, $\mathrm{KCl}$, and DPC working solutions after field pollution was determined using a laser particle size analyser. The working solution contained nanoparticles dispersed between $3 \mathrm{~nm}$ and $2 \mu \mathrm{m}$ (Figures 12), in which the particle size accounted for a large proportion of $0.1-0.5 \mu \mathrm{m}$ (Table 4 ). The particle size of the nanoparticles was smaller than the pore diameter, and they could easily enter the nanopores. This result further proves that the erosion and plugging of nanoparticles were 


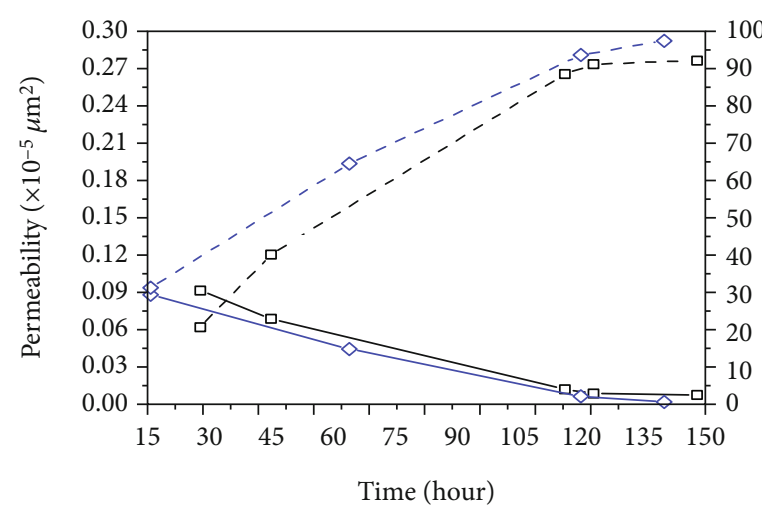

$\rightarrow \square$ Permeability of differential pressure $2 \mathrm{MPa}$

- $\square-$ Permeability of differential pressure $4 \mathrm{MPa}$

$\checkmark$ Damage rate of differential pressure $2 \mathrm{MPa}$

$-\diamond-$ Damage rate of differential pressure $4 \mathrm{MPa}$

(a) Distilled water

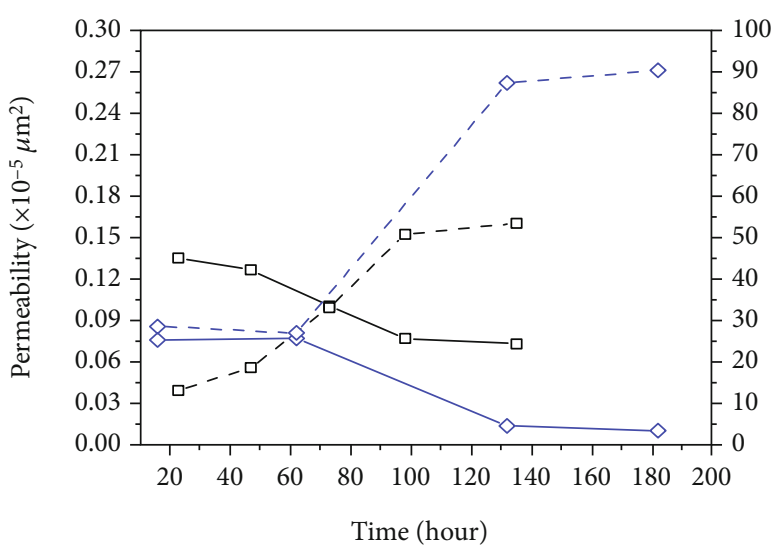

$\neg-$ Permeability of differential pressure $2 \mathrm{MPa}$

- - Permeability of differential pressure $4 \mathrm{MPa}$

$\checkmark-$ Damage rate of differential pressure $2 \mathrm{MPa}$

$-\diamond$ - Damage rate of differential pressure $4 \mathrm{MPa}$

(c) DPC

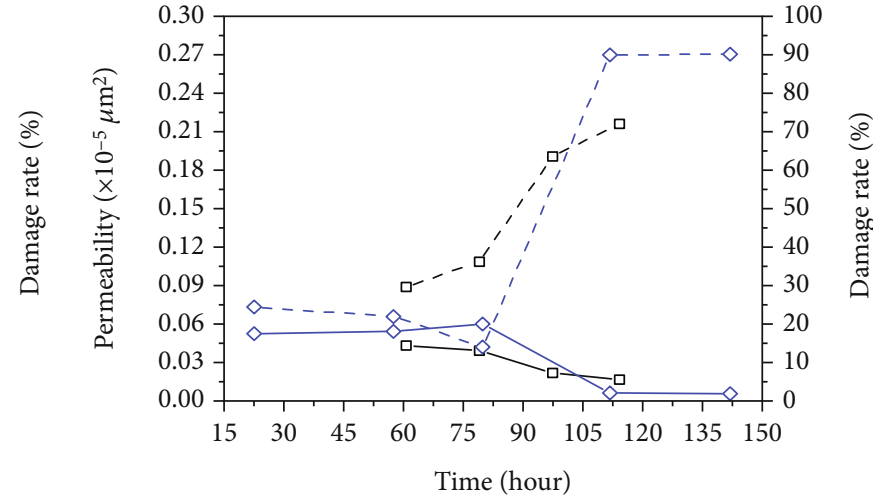

$\neg \square$ Permeability of differential pressure $2 \mathrm{MPa}$

- - Permeability of differential pressure $4 \mathrm{MPa}$

$\checkmark-$ Damage rate of differential pressure $2 \mathrm{MPa}$

$-\diamond-$ Damage rate of differential pressure $4 \mathrm{MPa}$

(b) $\mathrm{KCl}$

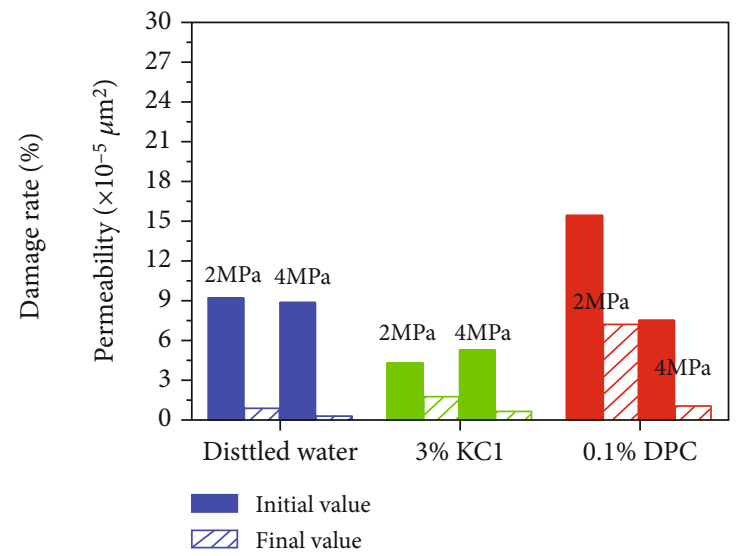

FIGURE 9: Effect of permeability damage rate under different pollution pressure differences.

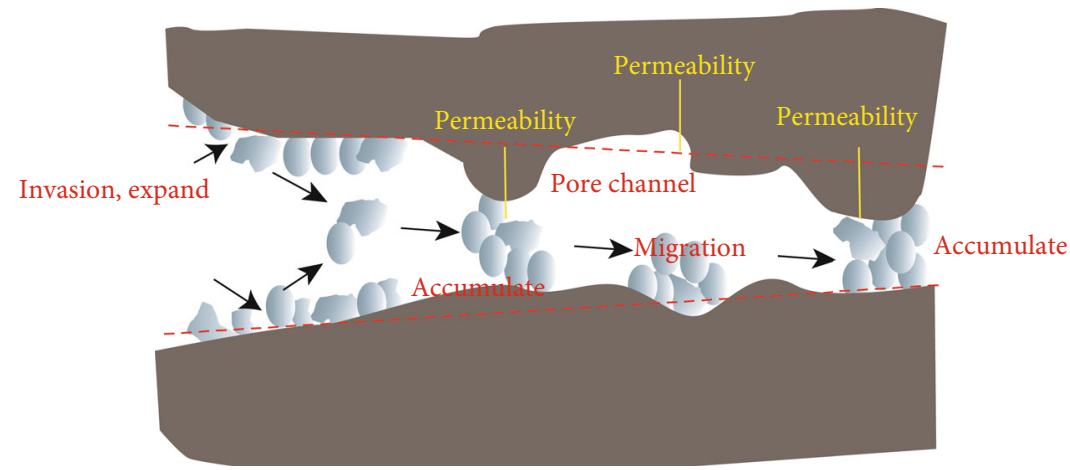

FIGURE 10: Influence of particle migration on permeability. 

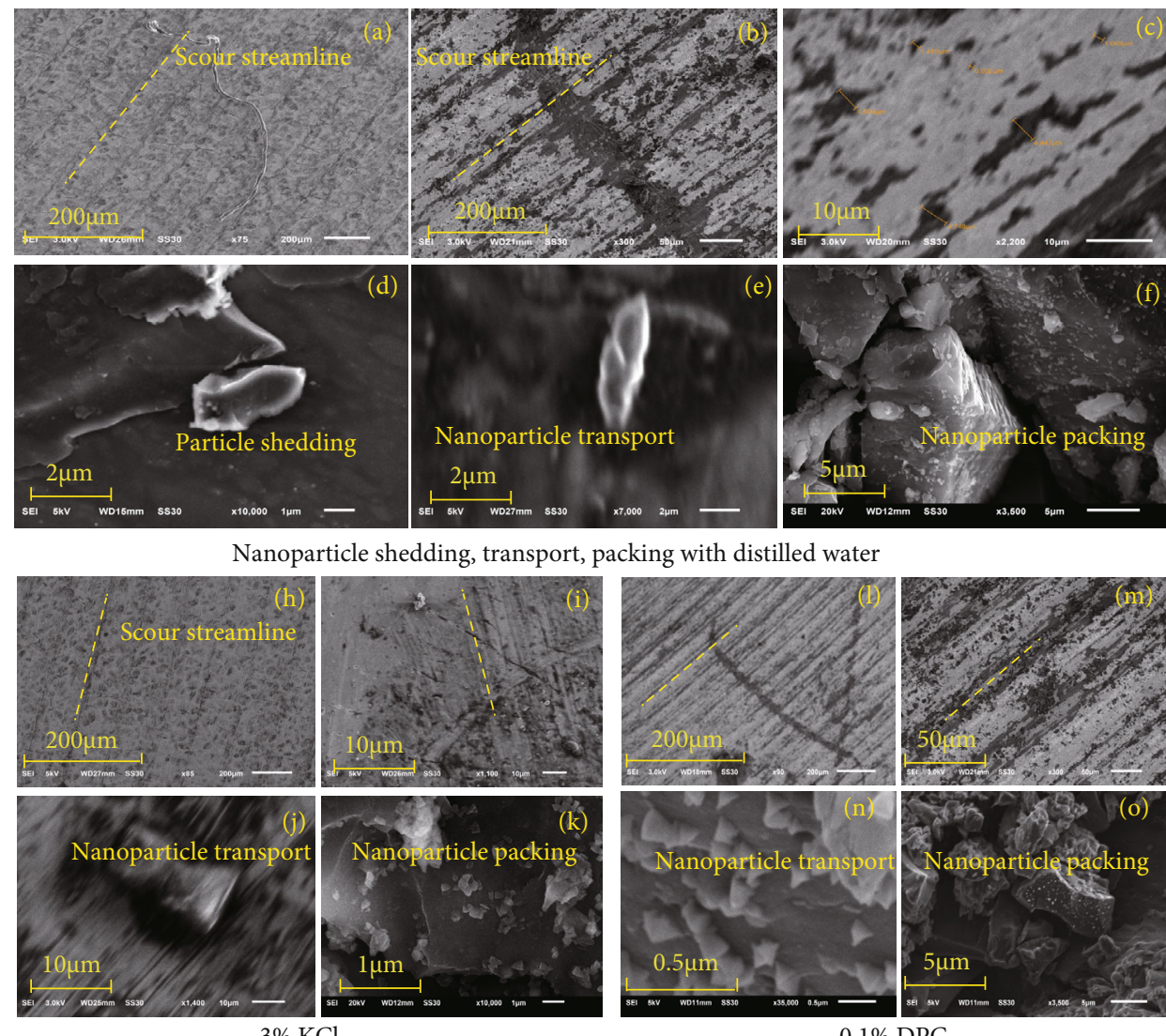

$3 \% \mathrm{KCl}$

$0.1 \% \mathrm{DPC}$

FIgURE 11: Micromorphology of coal sample after $\mathrm{KCl}$ scouring pollution.
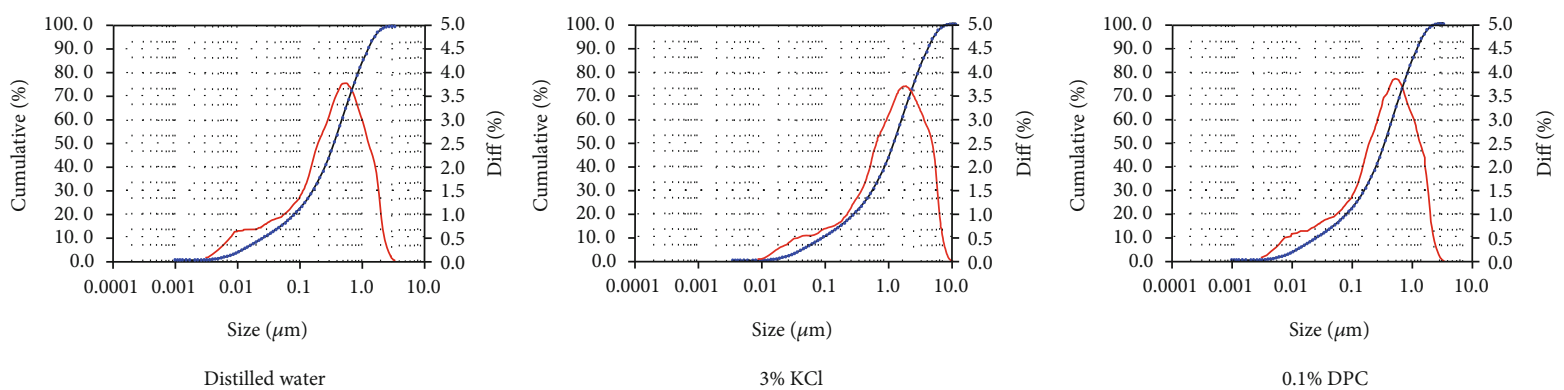

FIGURE 12: Distribution of solid particles in distilled water after pollution.

TABLe 4: Particle size and content distribution of the solid phase in the working liquid system after pollution.

\begin{tabular}{lccccccccccccc}
\hline Particle size $(\mu \mathrm{m})$ & 0.003 & 0.008 & 0.02 & 0.1 & 0.15 & 0.2 & 0.4 & 0.42 & 0.45 & 0.5 & Notes \\
\hline & 0.16 & 2.49 & 7.21 & 20.75 & 26.97 & 33.12 & 53.12 & 54.75 & 57.14 & 60.87 & Distilled water \\
Content distribution (\%) & 0.02 & 2.35 & 8.02 & 22.80 & 29.15 & 35.50 & 56.06 & 57.76 & 61.26 & 62.13 & KCl \\
& 0.01 & 1.98 & 7.22 & 23.23 & 29.76 & 38.05 & 59.68 & 62.08 & 64.15 & 65.21 & DPC \\
\hline
\end{tabular}

factors that affected the permeability reduction of the coal samples.

Compared with the permeability change in the coal sample under the pressure difference of $2 \mathrm{MPa}$, the permeability of the coal sample under the pressure difference of $4 \mathrm{MPa}$ exhibited a floating change. The greater the scour force was, the greater the effect on permeability was, which was mainly due to the migration of coal ash particles in the coal sample under the action of shearing fluid. Then, the coal reservoir was damaged.

DPC has a strong inhibition effect on the expansion of clay mineral components. From the perspective of microstructure morphology and solid particle distribution, although the inhibition can control the expansion and 
dispersion of clay in the coal sample, under the condition of a large pressure difference, particle migration blocks the seepage channel and affects the permeability of the reservoir. Therefore, coal reservoir protection should also consider protecting nanopores from plugging. Reasonable control of the production pressure difference can effectively reduce particle plugging.

\section{Summary and Conclusions}

The damage on the coal reservoir caused by permeability reduction resulting from the plugging of nanoparticles in coal cannot be ignored. Through the method of macroscopic permeability damage rate test and microscopic observation and analysis, this study proved that nanoparticle erosion and plugging are important factors of coal reservoir damage.

(1) When the working fluid entered a coal sample, a time limit exists for the water absorption of coal from the hydrophobic phase. If this time limit is not exceeded, then the clay mineral nanoparticles in the coal sample will not expand. Beyond this time limit, the clay mineral nanoparticles will expand via water absorption, destroy the potential balance between the original ions, cause the particles to disperse and move, block the seepage channel, and reduce permeability. Under the current experimental conditions, the time limit is between 114 and $118 \mathrm{~h}$

(2) For permeability damage, concentration is only an external manifestation, and viscosity is the internal cause. The higher the viscosity of the working fluid is, the more nanoparticles the fluid carries and the easier it is to block the pores of the coal reservoir and accelerate its damage. In this study, under the same initial permeability damage rate and pressure difference of coal samples, the viscosity and damage rate of the DPC fluid increased by two times, and permeability decreased by 1.21 times. The permeability of the reservoir was seriously reduced

(3) The permeability damage rate of a coal reservoir is sensitive to the pressure difference. An increase in the pressure difference causes the instability of clay mineral particles and promotes the dispersion and falling off of particles. Under the action of shear stress of the working fluid, coal ash particles migrate to the microcracks and pores of the coal reservoir. At the same time, an increase in the pressure difference makes the nanoparticles move deeper into the deep part of the coal reservoir, leading to the particles bridging the pore throat and reducing permeability. Plugging can reduce the permeability of coal samples by up to two orders of magnitude. Hence, no methane gas can be mined from the coalbed methane

(4) Selection of a low-concentration, water-soluble polymer fluid and reasonable reduction of the production pressure difference can effectively reduce the damage on reservoir nanopore permeability
(5) The advantage of this paper is to analyse the cause of nanopore plugging by means of pressure oscillation and a scanning electron microscope. However, in this paper, the matching effect of particle size and pore size should not be considered in the nanopore plugging of coal seams. Besides, an electron microscope can only observe pores in a small area; it cannot accurately analyse the particle size and pore size. In the future, further research could be conducted on the matching effect of particle size and pore size on pore plugging and the damage degree

\section{Data Availability}

All data generated or analysed during this study are included in this published article.

\section{Conflicts of Interest}

None of the authors have any conflicts of interest.

\section{Acknowledgments}

This research was supported by the PetroChina Innovation Foundation (no. 2019D-5007-0206) and Important National Science and Technology Specific Project of China (grant nos. 2016ZX05025-002-003 and 2016ZX05061-009).

\section{References}

[1] H. Xu, S. Zhang, X. Leng, D. Tang, and M. Wang, "Analysis of pore system model and physical property of coal reservoir in the Qinshui Basin," Chinese Science Bulletin, vol. 50, Supplement 1, pp. 52-58, 2005.

[2] W. Mingshou, T. Dazhen, and W. Yongpei, "Reservoir characteristics and enrichment mechanism of the coal-bed gas in the north of Qinshui Basin," Petroleum Geology and Experiment, vol. 28, no. 5, 2006.

[3] S. Gu, J. H. Cai, and D. W. Chang, "Reducing formation damage to low-porosity and low-permeability CBM reservoirs using calcium carbonate nanoparticles," Earth Science, vol. 40, no. 6, pp. 1093-1100, 2015.

[4] D. Ma, C. Liu, and C. Cheng, "New relationship between resistivity index and relative permeability," Journal of Energy Resources Technology, vol. 137, no. 3, 2015.

[5] S. Liu and K.-t. Wan, "Path of a solid inclusion embedded in a soft matrix subject to finger palpation," International Journal of Solids and Structures, vol. 203, pp. 151-156, 2020.

[6] J.-H. Cai, Y. Yuan, J.-J. Wang, X.-J. Li, and W.-J. Cao, “Experimental research on decreasing coalbed methane formation damage using micro-foam mud stabilized by nanoparticles," Journal of China Coal Society, vol. 38, no. 9, pp. 1640-1645, 2013.

[7] J. Wu, W. Zhou, S. Sun, S. Zhou, and Z. Shi, "Graptolitederived organic matter and pore characteristics in the Wufeng-Longmaxi black shale of the Sichuan Basin and its periphery," Acta Geologica Sinica-English Edition, vol. 93, no. 4, pp. 982-995, 2019.

[8] L. A. Féris, M. L. Souza, and J. Rubio, "Sorption of heavy metals on a coal beneficiation tailing material: II. Adsorptive 
particulate flotation," Coal Preparation, vol. 22, no. 5, pp. 235248, 2002.

[9] T. Gentzis, N. Deisman, and R. J. Chalaturnyk, "Effect of drilling fluids on coal permeability: impact on horizontal wellbore stability," International Journal of Coal Geology, vol. 78, no. 3, pp. 177-191, 2009.

[10] C. Li, L. Kong, M. Ostadhassan, and T. Gentzis, "Nanoscale pore structure characterization of tight oil formation: a case study of the Bakken formation," Energy \& Fuels, vol. 33, no. 7, pp. 6008-6019, 2019.

[11] Y. Chen, D. Joffre, and P. Avitabile, "Underwater dynamic response at limited points expanded to full-field strain response," Journal of Vibration and Acoustics, vol. 140, no. 5, 2018.

[12] Z. Zhu, S. Luo, Q. Feng, Y. Chen, F. Wang, and L. Jiang, “A hybrid DIC-EFG method for strain field characterization and stress intensity factor evaluation of a fatigue crack," Measurement, vol. 154, p. 107498, 2020.

[13] S. A. G. A. R. SHAH, E. V. G. E. N. I. A. PLAKA, M. A. T. H. E. W. SCHEY et al., "In-situ characterization of polymer matrix composites and progressive damage analysis of virtually reconstructed microstructures," in American Society for Composites 2020, 2020.

[14] K. Mosher, J. He, Y. Liu, E. Rupp, and J. Wilcox, "Molecular simulation of methane adsorption in micro-and mesoporous carbons with applications to coal and gas shale systems," International Journal of Coal Geology, vol. 109, pp. 36-44, 2013.

[15] Q. Yue, L. Guichuan, and L. Dongxian, "Development and application of degradable polymer drilling fluid for coal bed methane horizontal well," Journal of China Coal Society, vol. 40, Supplement 2, pp. 425-429, 2015.

[16] B. Ju and T. Fan, "Experimental study and mathematical model of nanoparticle transport in porous media," Powder Technology, vol. 192, no. 2, pp. 195-202, 2009.

[17] T. A. Moore, "Coalbed methane: a review," International Journal of Coal Geology, vol. 101, pp. 36-81, 2012.

[18] C. Zhai, L. Qin, S. Liu, J. Xu, Z. Tang, and S. Wu, "Pore structure in coal: pore evolution after cryogenic freezing with cyclic liquid nitrogen injection and its implication on coalbed methane extraction," Energy \& Fuels, vol. 30, no. 7, pp. 6009-6020, 2016.

[19] J. Dong, M. Chen, Y. Jin, G. Hong, M. Zaman, and Y. Li, "Study on micro-scale properties of cohesive zone in shale," International Journal of Solids and Structures, vol. 163, pp. 178-193, 2019.

[20] S. Yuan and B. Yang, "The fixed nodal position method for form finding of high-precision lightweight truss structures," International Journal of Solids and Structures, vol. 161, pp. 82-95, 2019.

[21] A. Mitra, S. Harpalani, and S. Liu, "Laboratory measurement and modeling of coal permeability with continued methane production: part 1 - laboratory results," Fuel, vol. 94, pp. 110-116, 2012.

[22] H.-L. Yang, W.-Y. Wang, and Z.-L. Tian, "Reservoir damage mechanism and protection measures for coal bed methane," Journal of China Coal Society, vol. 39, no. 1, pp. 158-163, 2014.

[23] G. Liu, H. Weng, Z. Song, and J. Ren, "Study on the adsorption mechanism of gas of deep coal seams based on the characteristics of the coal pore fractal medium," Journal of Computational and Theoretical Nanoscience, vol. 12, no. 9, pp. 27242731, 2015.
[24] C. Li, M. Ostadhassan, A. Abarghani, A. Fogden, and L. Kong, "Multi-scale evaluation of mechanical properties of the Bakken shale," Journal of Materials Science, vol. 54, no. 3, pp. 2133 2151, 2019.

[25] C. Ö. Karacan, F. A. Ruiz, M. Cotè, and S. Phipps, "Coal mine methane: a review of capture and utilization practices with benefits to mining safety and to greenhouse gas reduction," International Journal of Coal Geology, vol. 86, no. 2-3, pp. 121-156, 2011.

[26] L. Zheng, L. Kong, Y. Cao, H. Wang, Z. Han, and X. He, “The mechanism for fuzzy-ball working fluids for controlling \& killing lost circulation," Chinese Science Bulletin, vol. 55, no. 35, pp. 4074-4082, 2010.

[27] Q.-S. Yue, L.-F. Ju, G.-Z. Jiang, Z.-L. Tian, Y.-L. Hu, and Z.J. Huang, "Lab investigation on damage mechanism of coal reservoir for pinnate horizontal well based on coalbed methane," Journal of China Coal Society, vol. 37, no. 1, pp. 91-95, 2012.

[28] Y. Chen, P. Logan, P. Avitabile, and J. Dodson, "Non-model based expansion from limited points to an augmented set of points using Chebyshev polynomials," Experimental Techniques, vol. 43, no. 5, pp. 521-543, 2019.

[29] W.-A. Huang, "Study on damage mechanism and protection drilling fluid for coalbed methane," Journal of China Coal Society, vol. 37, no. 10, pp. 1717-1721, 2012.

[30] Y. Zhang, M. Lebedev, A. Al-Yaseri et al., "Nanoscale rock mechanical property changes in heterogeneous coal after water adsorption," Fuel, vol. 218, pp. 23-32, 2018.

[31] Y. Chen, B. Zhang, and S. Chen, "Model reduction technique tailored to the dynamic analysis of a beam structure under a moving load," Shock and Vibration, vol. 2014, 13 pages, 2014.

[32] Y. Chen, B. Zhang, N. Zhang, and M. Zheng, "A condensation method for the dynamic analysis of vertical vehicle-track interaction considering vehicle flexibility," Journal of Vibration and Acoustics, vol. 137, no. 4, 2015.

[33] G. N. Okolo, R. C. Everson, H. W. J. P. Neomagus, M. J. Roberts, and R. Sakurovs, "Comparing the porosity and surface areas of coal as measured by gas adsorption, mercury intrusion and SAXS techniques," Fuel, vol. 141, pp. 293-304, 2015.

[34] Y. Zhao, Y. Sun, S. Liu, K. Wang, and Y. Jiang, "Pore structure characterization of coal by NMR cryoporometry," Fuel, vol. 190, pp. 359-369, 2017.

[35] T. Hongming, G. Xiaoping, T. Haoxuan, Z. Liehui, Z. Feng, and H. Yun, "Evaluation method and damage mechanism of shale formation sensitivity damage," Journal of Central South University (Science and Technology), vol. 47, no. 4, pp. 12271236, 2016.

[36] S. Zhang and Y. D. Zhang, "Low-rank Hankel matrix completion for robust time-frequency analysis," IEEE Transactions on Signal Processing, 2020.

[37] Y. Chen, P. Avitabile, and J. Dodson, "Data consistency assessment function (DCAF)," Mechanical Systems and Signal Processing, vol. 141, p. 106688, 2020.

[38] Y. Chen, P. Avitabile, C. Page, and J. Dodson, “A polynomial based dynamic expansion and data consistency assessment and modification for cylindrical shell structures," Mechanical Systems and Signal Processing, vol. 154, p. 107574, 2021.

[39] J. Xu, B. Qiao, Z. Yang, Y. Chen, and X. Chen, "Optimal placement of blade tip timing sensors considering multi-mode vibration using evolutionary algorithms," in 2020 International Conference on Sensing, Measurement \& Data Analytics 
in the era of Artificial Intelligence (ICSMD), pp. 367-372, Xi'an, China, 2020.

[40] S. Zhou, D. Liu, Y. Cai, Z. Karpyn, and Y. Yao, "Comparative analysis of nanopore structure and its effect on methane adsorption capacity of Southern Junggar coalfield coals by gas adsorption and FIB-SEM tomography," Microporous and Mesoporous Materials, vol. 272, pp. 117-128, 2018.

[41] G. R. L. Chalmers and R. M. Bustin, "On the effects of petrographic composition on coalbed methane sorption," International Journal of Coal Geology, vol. 69, no. 4, pp. 288-304, 2007.

[42] Y. L. Yang, Z. H. Li, H. J. Ji, Y. J. Peng, and Z. Liu, "Effect of soluble organic matter in coal on its pore structure and methane sorption characteristics," Journal of Fuel Chemistry and Technology, vol. 41, no. 4, pp. 385-390, 2013.

[43] H. Ji, Z. Li, Y. Peng, Y. Yang, Y. Tang, and Z. Liu, "Pore structures and methane sorption characteristics of coal after extraction with tetrahydrofuran," Journal of Natural Gas Science and Engineering, vol. 19, pp. 287-294, 2014.

[44] E. T. Lilleodden, J. A. Zimmerman, S. M. Foiles, and W. D. Nix, "Atomistic simulations of elastic deformation and dislocation nucleation during nanoindentation," Journal of the Mechanics and Physics of Solids, vol. 51, no. 5, pp. 901-920, 2003. 